\title{
LOS RESTOS ÓSEOS HUMANOS DE NOMBRE DE JESÚS. EVIDENCIAS DE LA SALUD EN EL PRIMER ASENTAMIENTO EUROPEO EN PATAGONIA AUSTRAL
}

\author{
JORGE A. SUBY, RICARDO A. GUICHÓN* AND M. XIMENA SENATORE*"
}

\begin{abstract}
RESUMEN
De acuerdo con una variedad de fuentes históricas, los habitantes de Nombre de Jesús (1584), el primer asentamiento europeo en el Estrecho de Magallanes, habrían padecido situaciones de desnutrición y hambre, los cuales habrían llevado al fracaso de la expedición y la muerte de los pobladores. Los restos de este asentamiento permanecían en un halo de misterio por la ausencia de registro material. Recientemente se realizó una serie de campañas arqueológicas dirigidas por la Dra. M. Ximena Senatore, que dieron como resultado el hallazgo de los restos del asentamiento Nombre de Jesús y restos óseos humanos de algunos de sus pobladores. El objetivo de este trabajo es analizar y discutir las evidencias bioarqueológicas y paleopatológicas correspondientes a los restos óseos humanos hallados en el sitio arqueológico Nombre de Jesús, primer asentamiento europeo en Patagonia Austral, que permitan discutir las evidencias históricas. Los estudios consistieron en el análisis de lesiones patológicas de los restos óseos humanos hallados, tanto macroscópicas como a través de estudios radiográficos, tomográficos y densitométricos complementarios que colaboraron en el diagnóstico diferencial. Los resultados muestran abundantes signos de stress nutricional y metabólico, acompañado de lesiones producidas por infecciones inespecíficas, que sustentan las hipótesis previas de malnutrición. Este análisis posibilita por un lado conocer el estado de salud de los individuos que formaron parte de uno de los más grandes emprendimientos de colonización de la corona española y las causas de su fracaso. A su vez, resulta de interés como evidencia para evaluar uno de los primeros momentos de contacto aborigen-europeo y la posible introducción de patologías en Patagonia.
\end{abstract}

PALABRAS CLAVE: Nombre de Jesús, bioarqueología, paleopatología, contacto aborigen europeo.

Laboratorio de Ecología Evolutiva Humana, Facultad de Ciencias Sociales, Universidad Nacional del Centro de la Provincia de Buenos Aires. Calle 508 No 881, CP7631, Quequén, Buenos Aires, Argentina. e-mail: jasuby@hotmail.com

DIPA - IMHICIHU - CONICET y Universidad de Buenos Aires. Buenos Aires, Argentina. 


\section{THE HUMAN BONE REMAINS OF NOMBRE DE JESÚS. EVIDENCES OF HEALTH IN THE FIRST EUROPEAN SETTLEMENT IN SOUTHERN PATAGONIA}

\section{ABSTRACT}

According to historical sources, the inhabitants of Nombre de Jesús (1584), the first European settlement in the Strait of Magellan, could have suffered starvation episodes which produced the failure of the expedition and the death of the settlers. Recently, a serie of archaeological excavations resulted in the recovery of the rest of Nombre de Jesus' settlement and human bone remains of some of their inhabitants. The aim of this paper is to analyze the bioarchaeological and paleopathological evidences from the human bone remains recovered in the archaeological site Nombre de Jesús, which will allow the discussion of historical evidence. The studies included the analyses of macroscopic bone lesions and radiographic, tomographic and densitometric analyses, which helped with the differential diagnosis process. The results showed abundant signs of nutritional and metabolic stress, accompanied with unspecific infectious lesions, and these would lead to discuss whether the inhabitants of Nombre de Jesus could have suffered starvation episodes, as mentioned by historical sources. These analyses make it possible to study the health of the individuals of one of the biggest expeditions of the Spanish Crown, and they provide an interesting source of evidence to discuss the first period of native european contact and the introduction of new pathologies in Patagonia.

KEYWORDS: Nombre de Jesús, bioarchaeology, paleopathology, native european contact.

\section{INTRODUCCIÓN}

Las oportunidades de estudiar las etapas iniciales del contacto aborigen-europeo en América no son frecuentes. En el caso específico del proceso de contacto en el extremo austral del continente, se disponen principalmente de evidencias históricas y algunos restos óseos humanos, estos últimos en general pertenecientes a las poblaciones aborígenes, siendo escasos los restos de pobladores europeos. El primer intento de colonización del extremo sur de Patagonia se llevó a cabo a principios de 1584. La expedición española al estrecho de Magallanes, dirigida por Pedro Sarmiento de Gamboa, que diera como resultado la fundación del asentamiento Nombre de Jesús en el extremo continental sur de América, permanecía en un halo de misterio por la ausencia de registro material. Recientemente se realizó una serie de campañas arqueológicas dirigidas por la Dra. M. Ximena Senatore, que dieron como resultado el hallazgo de los restos del asentamiento Nombre de Jesús y restos óseos humanos de algunos de sus pobladores.

El objetivo de este trabajo es analizar y discutir las evidencias bioarqueológicas y paleopatológicas correspondientes a los restos óseos humanos hallados en el sitio arqueológico Nombre de Jesús, primer asentamiento europeo en Patagonia Austral. Este análisis posibilita por un lado conocer el estado de salud de los individuos que formaron parte de uno de los más grandes emprendimientos de colonización de la corona española y las causas de su fracaso. A su vez, resulta de interés como evidencia para evaluar uno de los primeros momentos de contacto aborigen-europeo y la posible introducción de patologías en Patagonia. Esperamos que el análisis de los restos humanos de los pobladores de Nombre de Jesús permita arrojar nueva luz sobre los trágicos sucesos que ocurrieron entre 1584 y 1587 en el Estrecho de Magallanes.

\section{Evidencias históricas del Primer Asentamiento Europeo en Patagonia Austral}

La historia de Nombre de Jesús es interesante y trágica a la vez. En primer lugar porque se trató de un plan de grandes proporciones, el cual tenía como objetivo la fortificación del estrecho de Magallanes para impedir el paso interoceánico a las embarcaciones británicas. Por otro lado, porque todos los colonos que arribaron a las costas del actual cabo Vírgenes perecieron en poco tiempo, y poco se conoce sobre este final. 
Como parte de un plan de protección del estrecho de Magallanes, la Corona Española bajo el reinado de Felipe II proyectó el establecimiento de dos fortificaciones al mando de Pedro Sarmiento de Gamboa. Los poblados serían emplazados en cada orilla de la angostura menor del estrecho de Magallanes, cerrando el paso a los corsarios británicos mediante una cadena que se extendería entre ellas. Para ello, el 9 de diciembre de 1581 zarparon 23 navíos que transportaban a 350 pobladores, 400 soldados para los fuertes del Estrecho y 600 para Chile, y 10 franciscanos (Saravia Viejo 1988); en total casi 1400 personas. Sin embargo, al estrecho de Magallanes arribaron aproximadamente 340 colonos, debido a varios naufragios y deserciones. El desembarco se realizó en la boca del Estrecho de Magallanes (actual cabo Vírgenes, Provincia de Santa Cruz) donde en febrero de 1584 se estableció el primer poblado, al que llamaron Nombre de Jesús, en un paraje al que se denominó Valle de las Fuentes debido a la disponibilidad de agua dulce. Un mes después un grupo de 94 soldados, bajo el mando de Sarmiento de Gamboa, inició una travesía por tierra a pie en dirección oeste con el propósito de fundar un segundo poblado donde los esperaría la única embarcación que había quedado en el Estrecho. Después de un viaje de más de $200 \mathrm{~km}$. fue fundada la ciudad del Rey Don Felipe (Barros 1978, 1991), en las proximidades de la actual ciudad de Punta Arenas (Chile).

Sarmiento de Gamboa permaneció en ese poblado hasta fines de mayo de 1584, cuando decidió, luego de ser víctima de una tempestad que lo alejó del Estrecho, emprender su partida hacia Río de Janeiro en la única embarcación que había quedado, con el fin de solicitar ayuda a la corona española. Diversos documentos escritos por Sarmiento de Gamboa al rey Felipe II relatan las experiencias sufridas por los pobladores, que durante esos primeros meses ya padecían la escasez de víveres, las dificultades para obtener alimentos, el aislamiento, la adversidad del clima y la hostilidad de los grupos indígenas (Pastells 1920, Rosenblat 1950).

La ausencia de respuesta por parte del rey Felipe II obligó a Gamboa a embarcarse rumbo a España, pero durante su viaje fue asaltado y capturado por una embarcación británica que lo llevó hacia Inglaterra. Al ser liberado un año después, debió pasar por Francia, donde encontró nuevos inconvenientes que impidieron su regreso a España, el cual se produjo en 1590 (Benítez 2004). Finalmente, el socorro para los colonos nunca llegó.

Sólo existe otro testimonio de lo ocurrido en Nombre de Jesús. Mientras Sarmiento de Gamboa solicitaba ayuda para los colonos, tres años después de la fundación de las ciudades, en enero de 1587, una nave inglesa bajo el mando de Thomas Cavendish encontró a menos de veinte sobrevivientes y embarcó sólo a uno de ellos, un soldado español llamado Tomé Hernández. Este único sobreviviente logró escapar en Chile, haciendo su primera declaración oficial sobre lo ocurrido en las ciudades de Nombre de Jesús y Rey Don Felipe ante las autoridades españolas (Barros 1978). Los relatos de Tomé Hernández como único sobreviviente conocido coinciden con los de Sarmiento de Gamboa para los primeros meses de los asentamientos, en los cuales se comenta la escasez de alimento, que los pobladores morían de hambre, y que al ser embarcado por Cavendish en 1587, sólo alrededor de 20 personas permanecían con vida (Barros 1978). Según Hernández, los pobladores de Nombre de Jesús habrían abandonado el asentamiento algunos meses después de su fundación a mediados de 1584, partiendo los sobrevivientes rumbo a Rey Felipe. Por lo tanto, Nombre de Jesús habría estado habitado por algo más de cinco meses (Barros 1978; Martinic 1978).

Las referencias históricas a las poblaciones del estrecho de Magallanes están inevitablemente asociadas a la experiencia del abandono y el hambre. Sin embargo, ciertos estudios plantean que los recursos disponibles en la región del estrecho de Magallanes podrían haber sido suficientes para el aprovisionamiento de víveres para los pobladores (Fernández 1990). Por lo tanto, se discute aún si los habitantes de Nombre de Jesús y Rey Don Felipe pudieron haber "muerto de hambre", como lo señalan las fuentes históricas (Barros, 1978; Fernández 1983, 1990; Martinic 1978; entre otros).

Hasta el momento, sólo referencias históricas daban cuenta de la suerte de los pobladores en Nombre de Jesús mientras que para Rey Don Felipe tanto la historia (Barros 1978, Martinic 2003) como la arqueología (Massone 1983; Ortiz Troncoso 1970, 1971a, 1971b, 1972, 1992) habían ofrecido interesantes miradas. 


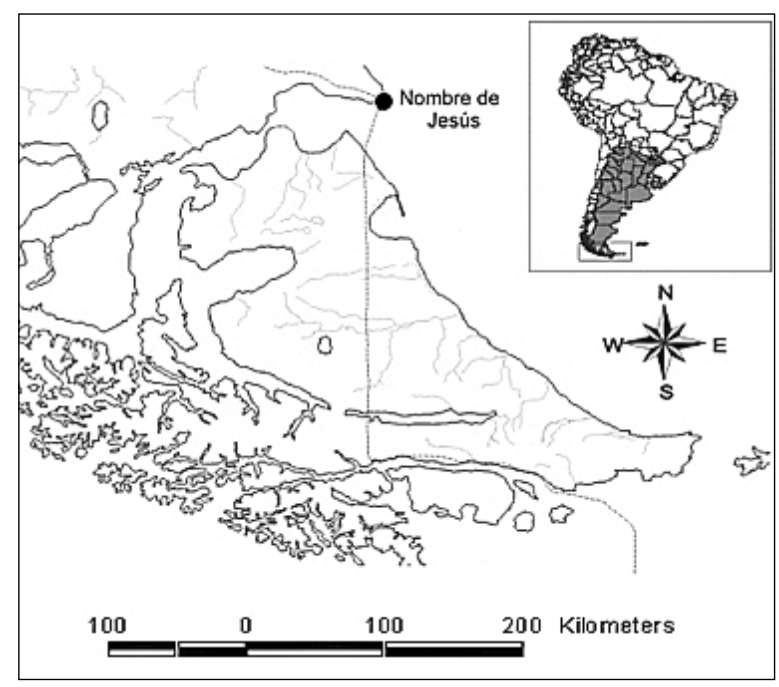

Fig. 1. Ubicación del sitio Nombre de Jesús, próximo al Cabo Vírgenes, Santa Cruz. Argentina.

\section{El hallazgo de Nombre de Jesús}

Diversos estudios y antecedentes señalaban al Valle de las Fuentes como lugar del asentamiento Nombre de Jesús (Fernández 1983, 1990; Martinic 1978). A partir del año 2003, en el marco del Proyecto Vida y Muerte en el Estrecho de Magallanes bajo la dirección de la Dra. M.X. Senatore, estudios sistemáticos confirmaron el punto exacto de los restos del poblado español, teniendo en cuenta los estudios arqueológicos desarrollados por Borrero y Franco (1999) sobre la base de la distribución de material cerámico en superficie 3 (Figura 1).

En la primera campaña de excavación de dicho proyecto en el año 2003, sobre la base del relevamiento topográfico y del estudio de perfiles, se eligieron dos puntos para ser comparados mediante pozos de sondeo. En uno de ellos se hallaron restos humanos que motivaron la ampliación de las excavaciones en las campañas de 2005 y 2006. La estratigrafía general del sector mostró un nivel superior caracterizado por la presencia de material arqueológico asignable a la

3 Por otra parte, esta zona también era conocida por una serie de excavaciones previas desarrolladas en busca de la ciudad del Nombre de Jesús entre las décadas del 1950 y 1980. Parte de las colecciones que resultaron de las mismas se conservan en el Museo Regional Provincial Padre Jesús Molina de la ciudad de Río Gallegos, mayoritariamente incompletas y sin indicación de una procedencia exacta (Senatore et al. 2007). ocupación española de fines del siglo XVI. Las muestras estudiadas, fundamentalmente la cerámica y los restos óseos, presentaban alta fragmentación, signos claros de erosión y meteorización muy semejantes a los materiales superficiales, así como presencia de marcas de raíces.

Bajo este nivel superior se definió el nivel 2 , cuyo comportamiento difiere significativamente del anterior y coincide con la identificación de la formación de un suelo. Los restos arqueológicos son escasos; sin embargo su preservación es buena y homogénea en este nivel (De Nigris et al. 2008). Se identificaron estructuras arqueológicas conformadas por alineación de ladrillos de adobes crudos que apoyan sobre la base de este depósito. Se consideró que este nivel estratigráfico se asocia a la ocupación del sitio (Senatore et al. 2007). Subyacente al nivel 2 se definió el nivel 3, donde fueron hallados en total cinco esqueletos humanos. El nivel 3 fue caracterizado fundamentalmente por la presencia de estructuras de enterratorios claramente identificables por el contraste entre los sedimentos que conforman los entierros y los espacios circundantes, características que sugieren una alta estabilidad para este depósito. Los esqueletos recuperados presentaron una alineación y disposición homogénea (Figura 2), todos ubicados con sus cabezas en dirección noreste. A su vez, el individuo NdJ 4 presentó una posición de entierro claramente cristiano, con ambos brazos cruzados sobre el tórax. Esto, además de la presencia de restos materiales diagnósticos vinculados al ritual de fundación de la ciudad (como una moneda española de plata de a 8 reales), permitió definir este espacio como un posible cementerio y asignarlo a la ocupación de Nombre de Jesús (Senatore et al. 2007).

Los esqueletos fueron hallados completos en todos los casos, con buen estado de conservación y ausencia de meteorización. Sólo algunos elementos de parte de los esqueletos presentan fracturas postmortem, con pérdida de tejido cortical y exposición del esponjoso en algunas epífisis de huesos largos y cuerpos vertebrales. El fechado radiocarbónico sobre huesos del primer esqueleto ${ }^{4}(\mathrm{NdJ} 1)$ obtenido

4 Diversas fuentes históricas mencionan el escorbuto como la principal causa de muerte entre navegantes durante el siglo XVI (Cupagge 1995; Maat 2004), aunque en muchos casos estos diagnósticos han sobreestimado el impacto de esta patología (Ortner 2003). 


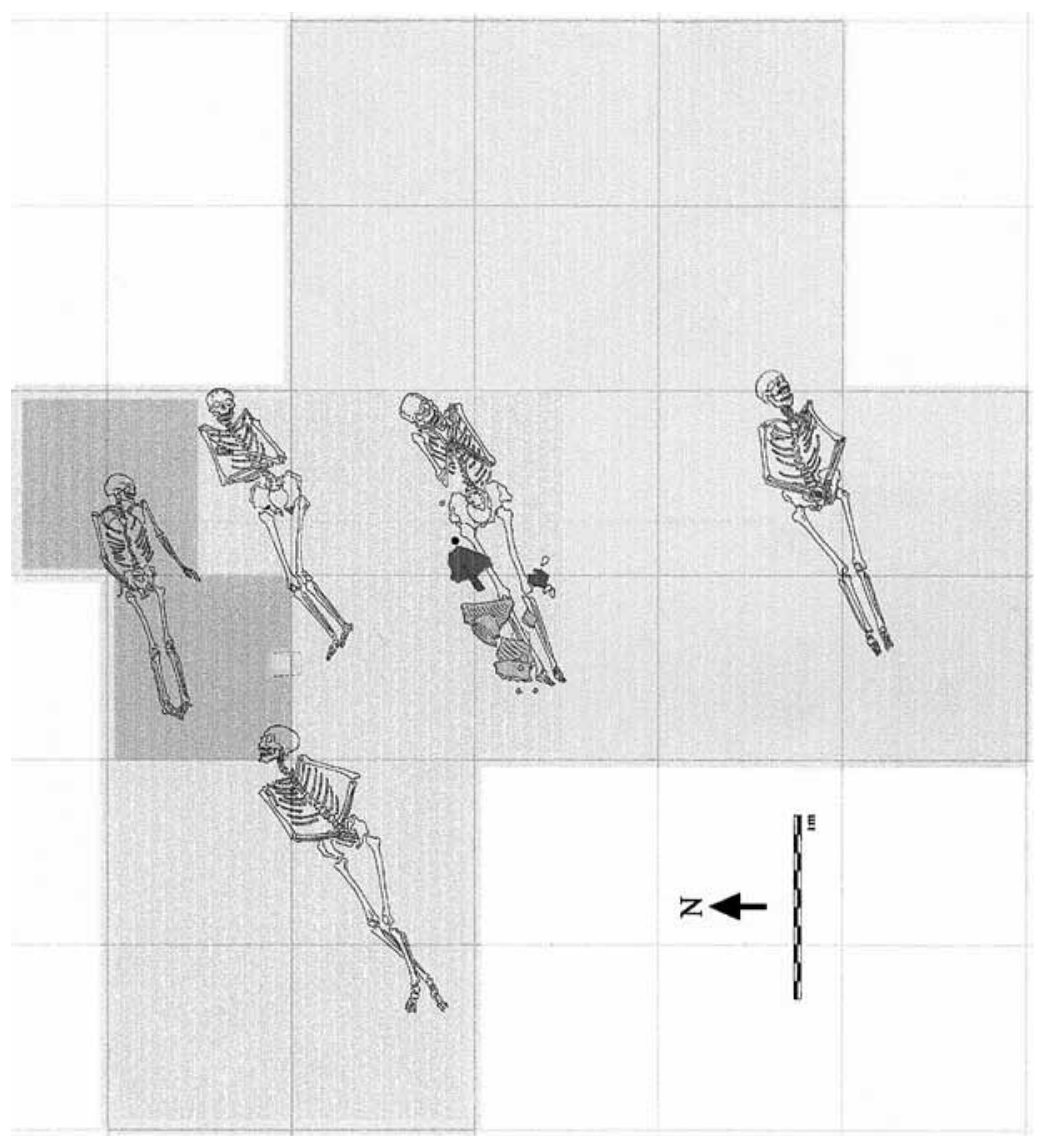

Fig. 2. Distribución en planta de los esqueletos hallados durante las excavaciones realizadas en el sitio Nombre de Jesús. El esqueleto 1 fue hallado en 2003 (izquierda); los esqueletos 2,3 y 4 en la campaña realizada en 2005 (centro); el esqueleto 5 durante la campaña de febrero de 2006 (derecha). Planta realizada por MX Senatore.

en 2003 indicó una antigüedad de $475 \pm 45$ años AP (Ua-22946), cuya calibración utilizando el Calib Radiocarbon Calibration Program, sugiere un rango temporal entre 1507 y $1697 \mathrm{AD}(0,902463$ data set: Marine/So). Este fechado es compatible con la fecha histórica del asentamiento, iniciado en febrero de 1584.

\section{MATERIALES Y MÉTODOS}

Como parte de los estudios sobre los restos esqueletales hallados, se realizaron estimaciones de sexo siguiendo los métodos propuestos por Buikstra y Ubelaker (1994), que incluyen las determinaciones morfológicas craneales (proyección de la cresta nucal, tamaño de proceso mastoides, espesor del margen supraorbital y proyección de eminencia mental) y la pelvis (arco ventral, concavidad subpúbica, la superficie de la rama isquiopúbica, la escotadura ciática, y el surco preauricular). Según estos indicadores, los individuos $\mathrm{NdJ} 2, \mathrm{NdJ} 4$ y $\mathrm{NdJ} 5$ corresponden al sexo masculino, mientras NdJ3 pertenece a un sujeto femenino (Tabla 1 ).

La edad a la muerte de los esqueletos fue determinada según los métodos de Todd y SucheyBrooks para el análisis de sínfisis púbica, la fusión de epífisis (Buikstra y Ubelaker 1994), y la metamorfosis del extremo esternal del cuarto arco costal (Isçan et al. 1984, en Bass 1995). Además se consideró la erupción dental como indicador de la edad, según el método de Ubelaker (1989). De acuerdo a estos indicadores, la edad de NdJ1 se estimó entre 10 y 12 años, de NdJ2 entre 18 y 22 años, NdJ3 entre 18 y 23, NdJ4 entre 20 y 24, y NdJ5 entre 22 y 26 años de edad a la muerte. 
Tabla 1. Estimaciones de edad, sexo y altura para los individuos hallados.

\begin{tabular}{cccc}
\hline Individuo & Edad $^{a}$ & Sexo $^{b}$ & Estatura $^{c}$ \\
\hline NdJ1 & 10 a 12 años & Indet. & ND \\
NdJ2 & 18 a 22 años & Masculino & $169,0(168,3-170)$ \\
NdJ3 & 18 a 23 años & Femenino & $168,3(165-173,1)$ \\
NdJ4 & 20 a 24 años & Masculino & $180,1(175,9-182)$ \\
NdJ5 & 22 a 26 años & Masculino & $164,23(163,6-165,1)$ \\
\hline
\end{tabular}

a: Datos obtenidos según el modelo de osificación de la terminación esternal de la cuarta costilla (Isçan et al. 1984 en Bass 1995), cierres epifisarios, sistema de Todd y Suchey-Brooks para sínfisis púbica, y morfología de la superficie auricular de la pelvis (en Buikstra y Ubelaker 1994).

b: Estimaciones realizadas según sistema de score de dimorfismo sexual del cráneo y pelvis (Buikstra y Ubelaker 1994).

c: Según Trotter y Gleser (1952; 1958) con corrección en 1977; en Tarli y Pacciani (1993), para tibia, fémur y humero.

La talla fue estimada siguiendo las formulas de regresión propuesta por Trotter y Glesser (1952 y 1958) para hombres y mujeres blancos, de acuerdo a la longitud de fémures, tibias y húmeros, mediante regresiones simples y múltiples. En todos los casos se tomaron medidas de la longitud total de ambos elementos, considerándose como valor final el valor medio (Tabla 1).

Con el propósito de conocer el estado de salud al momento de la muerte de los individuos hallados en Nombre de Jesús, se iniciaron evaluaciones de signos patológicos en los restos óseos. Como metodología de análisis se realizaron descripciones detalladas de los restos óseos siguiendo la metodología general propuesta por Campillo (2001): hipótesis diagnóstica, inspección visual de los materiales, evaluación de posibles lesiones pseudopatológicas y tafonómicas, variabilidad anatómica, identificación y descripción de lesiones, exámenes complementarios (radiológicos, tomográficos y densitométricos), diagnóstico diferencial y análisis de la fase evolutiva en que se encuentran las lesiones. Por último se propone, en los casos posibles, un diagnóstico asignable a algunas de las categorías etiológicas de las lesiones (infecciosas, nutricionales-metabólicas, osteoarticulares, traumáticas, congénitas y tumorales) siguiendo a Aufderheide y Rodríguez Martín (1998), Campillo (2001), Capasso et al. (1999), Larsen (1997), Ortner (2003) y Steinbock (1976), entre otros. Cada uno de los individuos fue estudiado individualmente, permitiendo obtener conclusiones finales a partir de la totalidad de la muestra.

En base a la información proveniente de fuentes históricas y las referencias paleopatológicas halladas en otros estudios realizados sobre muestras esqueletales pertenecientes a navegantes y poblaciones europeas medievales, se plantea como hipótesis diagnóstica para el estudio de los restos esqueletales hallados en Nombre de Jesús que los individuos habrían presentado estados patológicos atribuibles a déficit

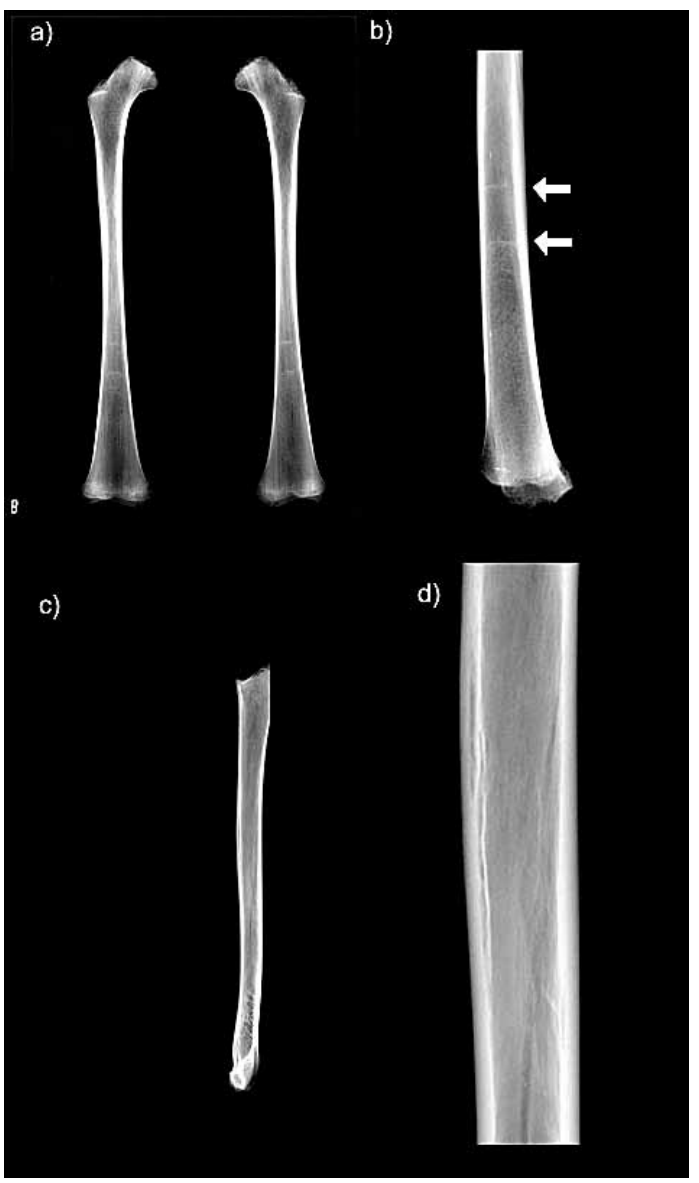

Fig. 3. Radiografías de huesos largos de NdJ1. Se observan líneas de Harris en el tercio sector distal de las diáfisis de ambos fémures: a) imágenes anteroposteriores y b) lateral del fémur derecho. Se observaron además alteraciones corticales en la radiografía mediolateral del húmero derecho (c), presentada en imagen ampliada en (d). 
nutricionales y estados de malnutrición, probablemente acompañados de patologías infecciosas asociadas. Respecto de este último punto, la presencia de signos patológicos infecciosos permitiría evaluar la posible introducción de enfermedades en Patagonia. De acuerdo con esta hipótesis, se realizaron estudios densitométricos que permiten evaluar el grado de mineralización ósea de la columna lumbar y el cuello del fémur, y estudios de la geometría de la sección transversal de huesos largos. Ambos tipos de análisis aportan información complementaria acerca de la salud nutricional al momento de la muerte de los individuos hallados en Nombre de Jesús.

\section{RESULTADOS}

La inspección macroscópica de los elementos óseos correspondientes al esqueleto NdJ1 mostró la presencia de hiperostosis porótica en ambos parietales y en el hueso occipital, activas al momento de la muerte, como única lesión ósea patológica macroscópica. Se realizaron estudios radiográficos de los elementos pertenecientes a este individuo, a fin de evaluar la presencia de lesiones que no sean percibidas en forma macroscópica. Las imágenes radiográficas mostraron la presencia de dos líneas de Harris en ambos fémures (Figura 3a y 3b), que por su ubicación sugieren la ocurrencia de dos periodos diferentes de stress. Estimaciones de la ubicación de las líneas de Harris respecto del extremo distal de los fémures realizadas siguiendo el método propuesto por Byers (1991; ver también Suter et al. 2008) sugieren que el primero de estos episodios se habría producido entre los 4 y 6 años y el segundo entre los 7 y 8 años. Se observaron además alteraciones corticales en radiografías laterales de húmeros, compatibles con el desarrollo de trastornos metabólico-nutricionales (Figura 3c y 3d).

En el caso del individuo NdJ2, se identificó la presencia de una leve escoliosis de la columna dorsal, con reducción de la altura medio lateral del lado izquierdo del cuerpo vertebral de T11, y de la columna lumbar, con disminución de la altura medio lateral izquierda del cuerpo de L3 y L5 (Figura 4). Además se registró una depresión circular de aproximadamente $1 \mathrm{~cm}$. de diámetro en la región

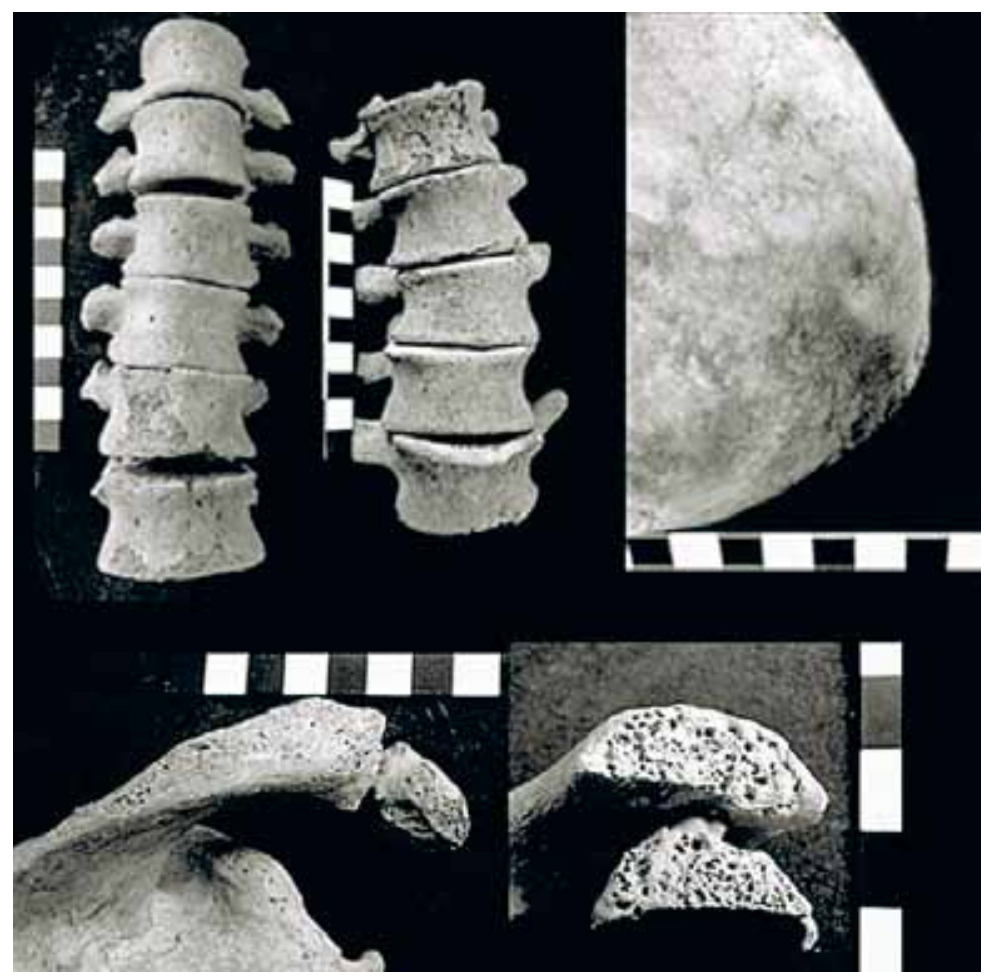

Fig. 4. Lesiones halladas en NdJ2. Arriba izquierda, lesiones osteoarticulares en vértebras dorsales y lumbares. Arriba derecha, lesión traumática compresiva en el cráneo.

Abajo, posible fractura y pseudoarticulación del acromion en la escapula derecha. 
posterior del hueso temporal izquierdo, posiblemente causado por un traumatismo craneal antemortem (Figura 4). También se registró una posible fractura del extremo distal del acromion de la escápula derecha, que presenta un proceso remodelatorio que permite descartar la posibilidad de un origen tafonómico (Figura 4). El hallazgo de ambas secciones del acromion en forma individual permite asumir que la fractura se remodeló sin fusión de las partes involucradas. Sin embargo, no se puede descartar en esta instancia que se trate de un caso de hueso acromial, es decir la ausencia de fusión del acromion como resultado de stress ocupacional (Capasso et al. 1999; Ponce com. per.).

Se identificaron además diversas lesiones periósticas, en el tercio medio del peroné derecho, $y$ lesiones de menor intensidad en la cara interna del tercio medio de la tibia derecha, que coincide con la ubicación de la lesión del peroné derecho, comúnmente asociadas a procesos infecciosos inespecíficos. Para evaluar su extensión se realizaron análisis radiográficos de las lesiones periósticas, así como de los demás huesos largos en busca de lesiones infecciosas. Las radiografías del peroné derecho mostraron un aumento de la densidad del tejido cortical al nivel de la lesión macroscópica observada, por lo que podría tratarse de una infección del tejido óseo (osteitis).

No se observó criba orbitalia, aunque se detectó la presencia de una ligera hiperostosis porótica activa de leve desarrollo, que se corrobora en la placa radiográfica lateral del cráneo. Asociado a este tipo de trastornos se observó la intensa porosidad del cuello femoral, el cual ha sido asignado a causas similares que las responsables de la hiperostosis porótica (Pérez Martín et al. 1999).

Las exploraciones macroscópicas del individuo NdJ3 muestran lesiones en las caras inferoposteriores de los cuerpos vertebrales T7 a T12 (Figura 5). Las lesiones se presentan de manera curva y con protrusión hacia el espacio medular. Asimismo, en estas vértebras no se observan lesiones que comprometan los arcos neurales (espondiloartrosis), ni la presencia de osteofitos o degeneración de las caras discales. Lesiones similares, aunque de menor intensidad se observan en la cara anteroposterior de los cuerpos T9 y T10. Estas lesiones son compatibles con las características desarrolladas por las hernias discales, generadoras de nódulos de Schmorl, lesiones observadas con amplio desarrollo en este individuo.

Se evidenciaron también diversas reacciones periósticas en huesos largos, en particular de los miembros inferiores. Se observó una extensa reacción perióstica en la tibia izquierda que ocupa la diáfisis en su cara anteromedial casi en su totalidad. Una lesión de similares características pero menor evolución se registró en la tibia derecha. Por otra parte, ambos peroné presentan lesiones periósticas sobre la cara anterodistal de las diáfisis, mayor en el peroné izquierdo. Estudios radiográficos permitieron determinar que las reacciones periósticas observadas macroscópicamente no comprometen el tejido cortical o la cavidad medular, por lo que quedaría descartada la evolución de osteitis y osteomielitis respectivamente.

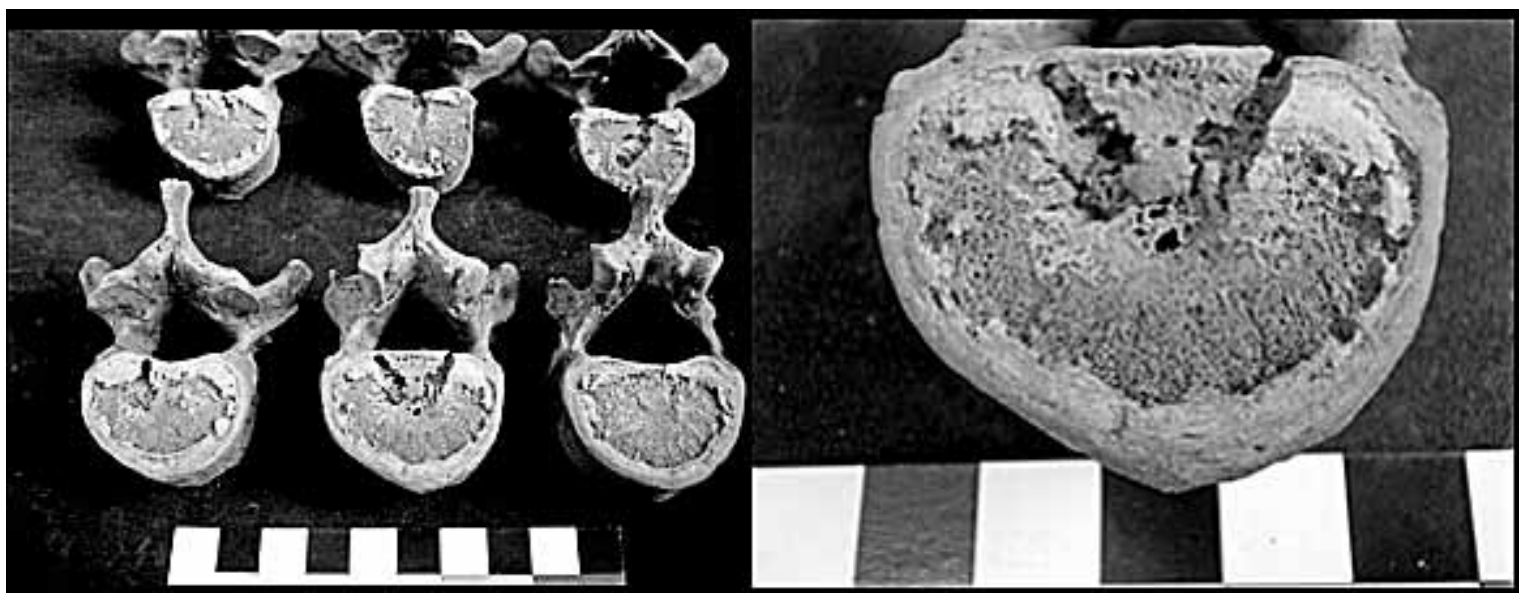

Fig. 5. Lesiones vertebrales en T7 a T12 observadas en NdJ3, probablemente asociadas a hernias discales. 


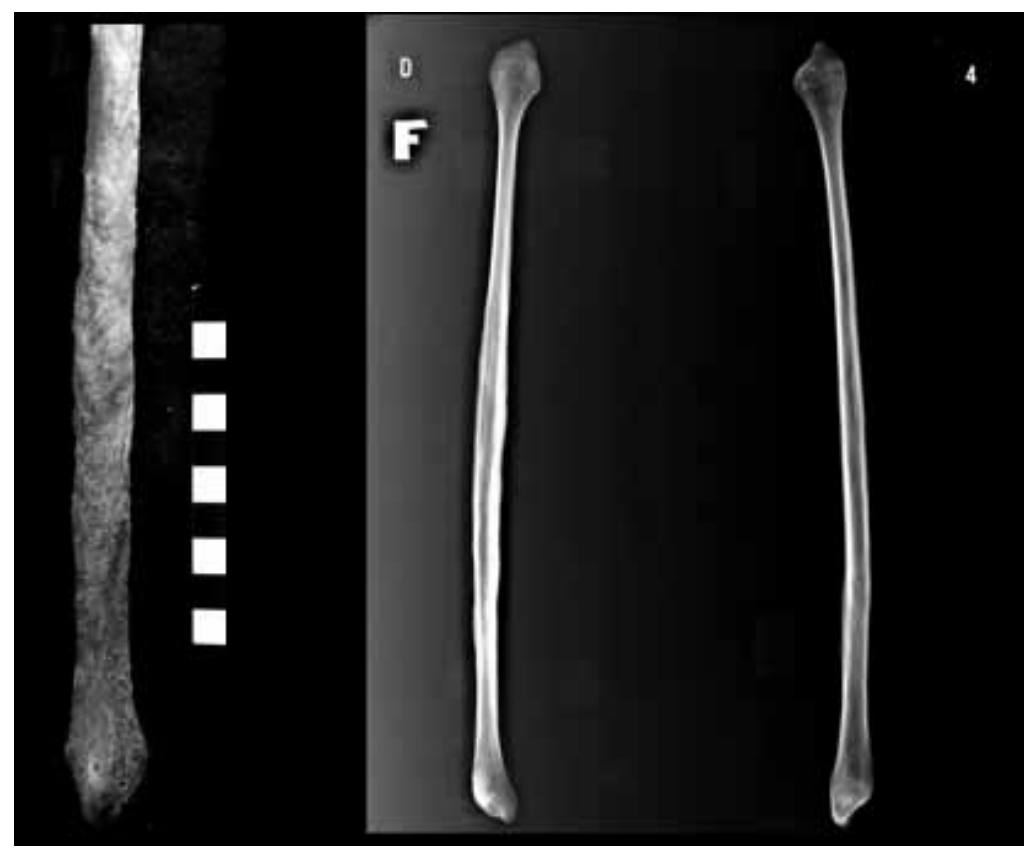

Fig. 6. Reacción periostica de marcado desarrollo en la diáfisis y metáfisis distal del peroné derecho. La imagen radiográfica muestra la mayor densidad del tejido cortical comprometido y la alteración del canal medular (osteomielitis).

La inspección macroscópica de los elementos de NdJ4 mostró la presencia de severas reacciones periósticas en la diáfisis y metáfisis distal del peroné derecho, y en la diáfisis y metáfisis distal de la tibia derecha (Figura 6). Para evaluar la extensión de estas lesiones se realizaron radiografías anteroposteriores y lateromediales de estos elementos. Las radiografías obtenidas muestran en el caso del peroné alteraciones del tejido cortical que afectan a su vez el canal medular, por lo que la lesión infecciosa podría haber ocasionado la contaminación de la medula (osteomielitis). Este tipo de patologías comúnmente produce la diseminación del foco infeccioso por vía hemática (septicemia). En este caso no se observaron lesiones periósticas en otros elementos óseos, por lo que podría considerarse que la muerte del individuo no habría permitido el desarrollo otras lesiones infecciosas óseas. Además se identificó la presencia de leves reacciones hiperostósicas activas en el occipital, acompañadas de porosidad bilateral del cuello del fémur.

Los elementos que componen el esqueleto de NdJ5 presentaron escasos indicios macroscópicos de lesiones patológicas. Se evidenció una leve hiperostosis porótica en el occipital, así como también líneas de hipoplasia del esmalte dental. Al igual que en los otros individuos estudiados, se registró una leve reacción perióstica sobre el peroné derecho, que no mostró lesión del tejido cortical o el área medular en las imágenes radiográficas realizadas.

\section{Patologías dentales}

Se realizaron evaluaciones de las lesiones dentales macroscópicas, complementadas con estudios radiográficos que permitieron profundizar los análisis. Sobre los materiales esqueletales se cuantificaron las piezas dentales presentes, numero de piezas erupcionadas, las pérdidas ante y postmortem y la frecuencia de caries y abscesos, cuyos resultados se muestran en la Tabla 2 . Como se observa, los individuos NdJ1 y NdJ2 presentan sólo 28 dientes erupcionados, debido a la ausencia de los terceros molares. En el caso de NdJ1 se observó en la radiografía dental panorámica los gérmenes incluidos en los maxilares de tales piezas dentales. Por el contrario, la imagen radiográfica de NdJ2 no presentó las piezas correspondientes a los terceros molares (agenesia), por lo que no se espera en este caso su erupción, independientemente de su edad. Ambos individuos no presentaron pérdidas dentales antemortem, a diferencia de los restantes individuos de la muestra. 
Tabla 2. Observaciones macroscópicas de las piezas dentarias de los individuos de Nombre de Jesús.

\begin{tabular}{|l|c|c|c|c|c|}
\cline { 2 - 6 } \multicolumn{1}{c|}{} & NdJ 1 & NdJ 2 & NdJ 3 & NdJ 4 & NdJ5 \\
\hline Alvéolos estudiados & 28 & 28 & 30 & 32 & 32 \\
\hline Dientes no erupcionados & 4 & 4 & 2 & 0 & 0 \\
\hline Dientes Presentes & 28 & 28 & 28 & 30 & 30 \\
\hline Perdidas antemortem & 0 & 0 & 2 & 2 & 1 \\
\hline Perdidas postmortem & 0 & 0 & 0 & 0 & 2 \\
\hline Dientes con Caries & 0 & 1 & 5 & 6 & 1 \\
\hline Dientes con Abscesos & 2 & 1 & 0 & 5 & 0 \\
\hline
\end{tabular}

Al mismo tiempo, salvo el individuo NdJ1, todos los individuos de la muestra presentan caries, siendo NdJ3 y NdJ4 los que mostraron mayor cantidad (5 y 6 respectivamente). En NdJ4 se acompañan además de un amplio número de abscesos y la pérdida de dos piezas dentales antemortem. Todos los individuos presentaron, en mayor o menor medida, líneas de hipoplasia del esmalte dental (Figura 7). A su vez, NdJ4 posee abundantes depósitos de sarro y retracción alveolar. Las imágenes radiográficas obtenidas a partir de ambos maxilares de NdJ5 (Figura 7) permitieron observar la retención intraósea con posición angulada del canino superior derecho permanente, como variación anatómica.
Osteopenia, Osteoporosis y

Desmineralización Osea

Dadas las expectativas de trastornos nutricionales y metabólicos para los restos de Nombre de Jesús, se realizaron estudios de la densidad mineral ósea en la columna lumbar y cuello de fémur que pudieran aportar información complementaria a las evidencias macroscópicas. Una de las condiciones de desmineralización ósea más frecuente en situaciones de stress nutricional es la osteopenia, un trastorno metabólico caracterizado por la reducción de la masa mineral ósea, que por deterioro microestructural de los tejidos esqueletales incrementa el riesgo de frac-

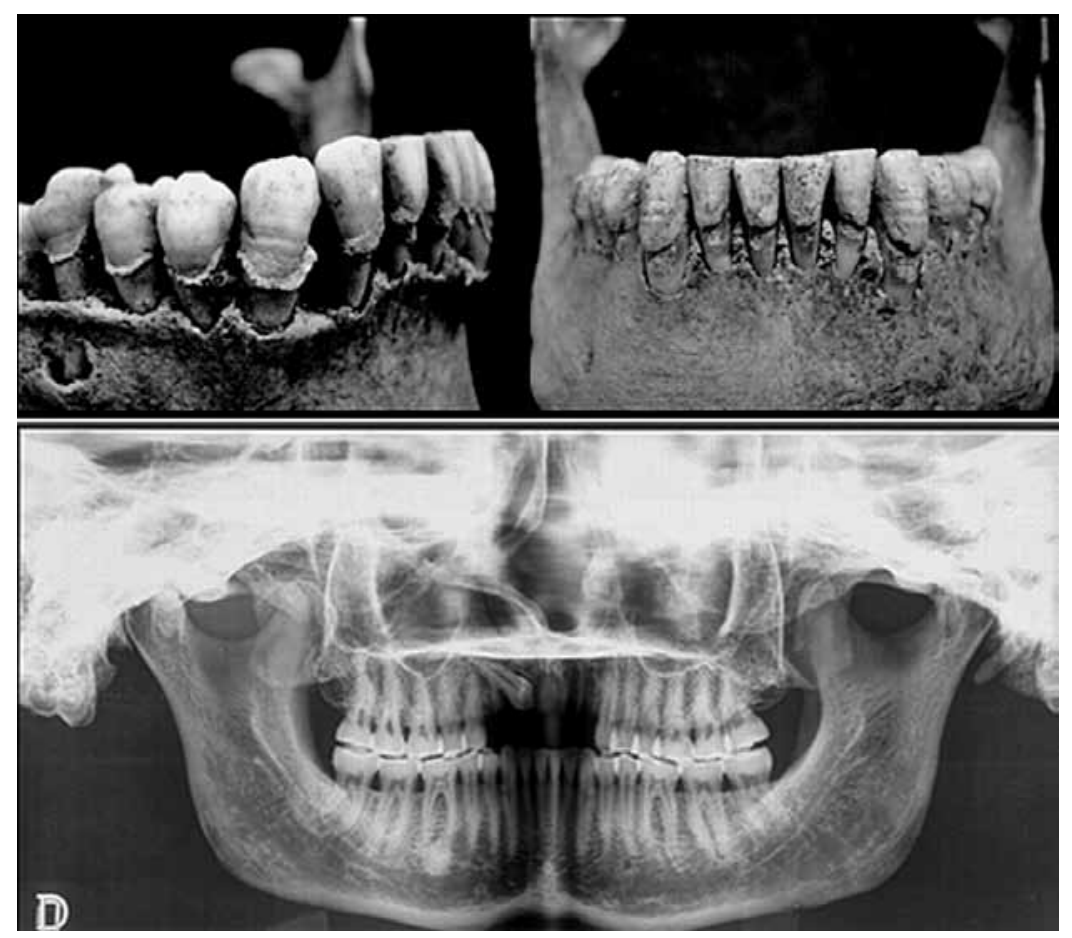

Fig. 7. Arriba: Líneas de hipoplasia del esmalte dental en NdJ4 (izquierda) y NdJ5 (derecha). Abajo: Radiografía panorámica dental de NdJ5. 
tura, condición conocida como osteoporosis (Levis y Altman 1998). La osteopenia y la osteoporosis están asociadas normalmente con múltiples factores, que además de la edad avanzada, incluyen el sexo, la actividad física y la relación músculo-hueso que afectan la acción mecánica a la cual los tejidos óseos responden, las condiciones nutricionales, factores genéticos y ambientales, y otros culturales como el consumo de tabaco.

La pérdida de masa ósea ha sido evaluada en poblaciones arqueológicas provenientes de distintas regiones geográficas, incluyendo principalmente series esqueletales de América del Norte, Europa y África (Agarwal et al. 2004; Ekerman et al. 1995; Kneissel et al. 1997; Lees et al. 1993; Mays, 1996, 1999, 2006; Mays et al. 1998; Mays et al. 2006; entre otros). En este contexto, los estudios de la masa mineral ósea en el pasado colabora como una fuente de información relevante para mejorar la comprensión de los mecanismos de la biología esqueletal que afectan la arquitectura ósea, a la vez que proporciona evidencias acerca de la salud de las poblaciones pretéritas. En este caso, el análisis de la densidad mineral ósea permitió estudiar la posible prevalencia de osteopenia en los restos esqueletales de los individuos que pertenecieron a la población de Nombre de Jesús, y discutir las hipótesis diagnósticas planteadas.

La técnica empleada comúnmente para evaluar el nivel de densidad mineral ósea es la Dual X-ray Absorptiometry (DXA). En la evaluación de osteopenia y osteoporosis, la metodología convencional empleada es la contrastación de los valores de DMO obtenidos en los individuos estudiados, con los valores obtenidos para una población actual considerada normal, generalmente de entre 20 y 30 años de edad. El nivel de reducción de la DMO respecto de estos valores normales indica la intensidad de la desmineralización ósea, representados por jóvenes considerados normales, aquellos que se encuentran entre un desvío y dos desvíos estándar por debajo de la DMO normal es considerada osteopenia, y aquellos en los cuales la DMO es menor en más de dos desvíos estándar a los valores normales corresponden a osteoporosis, según los criterios propuestos por la Organización Mundial de la Salud (OMS, 1984) y empleados comúnmente en el diagnóstico clínico. Por lo tanto, esta fue la metodología seleccionada para el estudio de la mineralización de los restos óseos humanos de Nombre de Jesús, y comparable a la empleada en otras poblaciones del pasado (Kneissel et al. 1997; Mays 2006). Los valores de referencia empleados en este caso fueron los proporcionados por el equipamiento densitométrico disponible (Hologic QDR-4500, Hologic Inc, Bedford, MA, USA), facilitados por el Hospital Privado de Comunidad, Mar del Plata, Argentina, y que corresponden a una población actual hispana, tanto de hombres como de mujeres. Aunque la variabilidad interpoblacional de la DMO dificulta las comparaciones entre poblaciones actuales y del pasado, se carecen de valores de densidad mineral ósea para poblaciones medievales españolas, de manera que esta representa la única posibilidad de comparación diagnóstica de los valores densitométricos. Como aproximación a valores temporalmente próximos, se contrastaron los datos correspondientes a Nombre de Jesús con aquellos obtenidos en estudios de otras poblaciones medievales, registrados a partir de muestras esqueletales de poblaciones de Inglaterra y Noruega (Mays et al. 2006), estudiados con el mismo equipamiento y similares metodologías.

Se incluyeron en este estudio aquellos materiales que estuvieran completos, no dañados y sin signos externos de erosión en el área a ser escaneada mediante DXA. Debido a la progresión de la DMO con la edad, la identificación de la edad a la muerte de los individuos estudiados resulta crítica. En este caso, se incluyeron sólo los individuos adultos, por lo que se descartó por este motivo el individuo $\mathrm{NdJ} 1$, en el cual los factores ontogénicos que determinan la masa mineral podrían representar un sesgo significativo. Se realizaron por lo tanto densitometrías óseas de las vértebras lumbares y del cuello de fémur de los cuatro individuos restantes. Las imágenes obtenidas permiten estudiar la DMO de áreas de interés de los cuerpos vertebrales, y en forma automática la evaluación del cuello del fémur, según el protocolo estándar de estudios densitométricos.

Los resultados alcanzados en la evaluación de la DMO de cuello de fémur se muestran en la Tabla 3. En el caso de los estudios sobre cuello de fémur se observa que los individuos NdJ2, NdJ3 y NdJ4 presentan valores estimados de DMO entre 1 y dos desvíos estándar por debajo de la media correspondiente a los valores normales pertenecientes una población española actual. En estas condiciones los resultados serían compatibles con 
Tabla 3. Valores de DMO de cuello de fémur de los individuos hallados en Nombre de Jesús.

\begin{tabular}{|c|c|c|c|c|c|c|}
\hline \multirow{2}{*}{ ESQUELETO } & \multicolumn{2}{|c|}{ FEMUR DERECHO } & \multicolumn{2}{c|}{ FEMUR IZQUIERDO } & \multicolumn{2}{c|}{ MEDIA } \\
\cline { 2 - 6 } & DMO & T & DMO & T & DMO & T \\
\hline 2 & 0,71 & $-2,04$ & 0,757 & $-1,68$ & 0,733 & $-1,86$ \\
\hline 3 & 0,697 & $-1,84$ & 0,688 & $-1,56$ & 0,692 & $-1,7$ \\
\hline 4 & 0,826 & $-1,15$ & 0,793 & $-1,4$ & 0,809 & $-1,275$ \\
\hline 5 & 0,971 & $-0,65$ & 0,89 & $-0,73$ & 0,930 & $-0,69$ \\
\hline
\end{tabular}

Tabla 4. Valores de DMO de Nombre de Jesús y poblaciones medievales de Inglaterra y Noruega.

\begin{tabular}{|l|c|c|c|}
\hline & Nombre de Jesús & Trondheim (Inglaterra) & Wharram Percy (Noruega) \\
\hline Mujeres (18 a 29) & 0,692 & $\begin{array}{c}0,953 \text { (normales) } \\
0,620 \text { (con fracturas osteoporóticas) }\end{array}$ & 0,951 (normales) \\
\hline Hombres (18 a 29) & 0,815 & $\begin{array}{c}0,981 \\
0,798 \text { (con fracturas osteoporóticas) }\end{array}$ & 0,988 (normales) \\
\hline
\end{tabular}

el grado de desmineralización ósea considerado como osteopenia. En el caso del individuo NdJ5 los valores obtenidos se incluyen dentro de los valores normales esperados actualmente.

Al comparar los valores hallados en Nombre de Jesús con los correspondientes a otras poblaciones medievales, se observa que los valores de los individuos NdJ2 y NdJ4, de entre 18 y 26 años, son semejantes a los obtenidos en individuos mayores de 50 años y considerados osteoporóticos en poblaciones inglesas y noruegas de entre el siglo X y
XVI (Tabla 4). Por el contrario, el individuo NdJ5 presentó valores similares a los correspondientes a individuos de entre 18 y 29 años, según Mays et al. (2006), considerados normales. Por último, el individuo NdJ3, correspondiente a un individuo femenino de entre 18 y 23 años, presenta valores similares a aquellos presentados por Mays et al. (2006) para mujeres mayores de 50 años de edad con diagnóstico de osteoporosis.

No se disponen de valores densitométricos de cuerpos vertebrales para poblaciones antiguas que

Tabla 5. Valores de DMO de cuerpos vertebrales lumbares de los individuos hallados en Nombre de Jesús.

\begin{tabular}{|c|c|c|c|c|c|}
\hline & VERTEBRAS LUMBARES & $\mathrm{DMO}$ & $\mathrm{T}$ & DMO MEDIA & T MEDIA \\
\hline \multirow{5}{*}{ ESQUELETO 2} & 1 & 0,702 & $-2,78$ & \multirow{5}{*}{0,833} & \multirow{5}{*}{$-2,312$} \\
\hline & 2 & 0,86 & $-2,12$ & & \\
\hline & 3 & 0,89 & $-1,94$ & & \\
\hline & 4 & 0,879 & $-2,42$ & & \\
\hline & 5 & 0,838 & $-2,3$ & & \\
\hline \multirow{5}{*}{ ESQUELETO 3} & 1 & 0,758 & $-1,52$ & \multirow{5}{*}{0,525} & \multirow{5}{*}{$-1,488$} \\
\hline & 2 & 0,968 & $-0,54$ & & \\
\hline & 3 & 0,908 & $-1,6$ & & \\
\hline & 4 & 0,87 & $-2,24$ & & \\
\hline & 5 & $-0,878$ & $-1,54$ & & \\
\hline \multirow{5}{*}{ ESQUELETO 4} & 1 & 0,762 & $-2,24$ & \multirow{5}{*}{0,918} & \multirow{5}{*}{$-1,546$} \\
\hline & 2 & 0,875 & $-1,99$ & & \\
\hline & 3 & 1,008 & $-0,87$ & & \\
\hline & 4 & 1,023 & $-1,11$ & & \\
\hline & 5 & 0,924 & $-1,52$ & & \\
\hline \multirow{5}{*}{ ESQUELETO 5} & 1 & 0,953 & $-1,2$ & \multirow{5}{*}{1,103} & \multirow{5}{*}{$-0,308$} \\
\hline & 2 & 1,056 & $-0,67$ & & \\
\hline & 3 & 1,231 & $-0,21$ & & \\
\hline & 4 & 1,256 & 0,93 & & \\
\hline & 5 & 1,023 & $-0,39$ & & \\
\hline Valores Medios & & & & $\mathrm{O}, 844$ & $-1,413$ \\
\hline
\end{tabular}


permitan la comparación con grupos humanos de similares características. No obstante, los resultados logrados a partir de mediciones de DMO de los cuerpos vertebrales presentan valores disminuidos compatibles con osteopenia para los individuos NdJ2, $\mathrm{NdJ3}$ y NdJ4 respecto de poblaciones actuales, y un valor que podría considerarse dentro de los límites normales para el individuo NdJ5 (Tabla 5).

\section{Análisis de la Geometría de la Sección} Transversal de Huesos Largos

Se realizaron imágenes tomográficas mediante pQCT (peripheral Quantitative Computed Tomography) en el Centro de Estudios del Metabolismo Fosfocálcico (Universidad de Rosario, Argentina) sobre las tibias a dos niveles: 35\% y 65\% de la longitud total a partir del extremo distal. Las imágenes digitales de los cortes transversales de tibia fueron analizadas a través del software ImageJ producido por el National Institutes of Health -USA (http:// rsb.info.nih.gov/ij). Se estudiaron las imágenes obtenidas en forma cualitativa y cuantitativa a través del estudio del espesor cortical, área total y área medular, y segundo momento de área y momento polar de la sección transversal de huesos largos de miembros inferiores.

En la Figura 8 se muestran imágenes obtenidas mediante pQCT de la sección transversal de tibias de los individuos de Nombre de Jesús. Aunque se realizaron imágenes tomográficas de todos los individuos de Nombre de Jesús, no se incluyó al esqueleto $\mathrm{NdJ1}$ en los análisis biomecánicos por tratarse de un niño, y cuyo desarrollo óseo se encuentra incompleto. Los elementos estudiados presentan en el caso de $\mathrm{NdJ} 2$, NdJ3 y NdJ4, a diferencia de NdJ1 y NdJ5, avanzada reabsorción del tejido cortical, conocido como remodelación haversiana (Ortner 2003), en la cual el tejido cortical es en parte reabsorbido y trabeculizado como respuesta a los requerimientos metabólicos producidos por déficit nutricionales. Similares manifestaciones fueron observadas en las imágenes obtenidas a nivel del 65\% de la longitud total de las tibias (Figura 8), con mayores superficies de reabsorción, en general afectando toda la superficie endóstica.

Estas impresiones cualitativas observadas en las imágenes tomográficas fueron corroboradas mediante las interpretaciones de indicadores biomecánicos de la geométrica de los cortes seccionales transversales. El análisis muestra la reducción del área cortical (CA) respecto del área total (TA) para cada uno de los individuos, indicadores asociados a la nutrición y el metabolismo. Como se observa en la Figura 9 el área cortical en el 35\% de la sección transversal de las tibias para los individuos de Nombre de Jesús es menor que aquellas estimadas para una pequeña muestra de individuos cazadores recolectores de Patagonia austral con similares valores de área total. Sólo el individuo NdJ5, que mostró valores de TA menores respecto de los demás individuos presentó un CA más próximo a las de cazadores recolectores con geometrías óseas similares. A su vez, es el individuo de los hallados en Nombre de Jesús que menor área medular (MA) presenta en relación al TA y CA, explicado posiblemente por la ausencia de reabsorción cortical observada en las imágenes tomográficas. Similares resultados fueron observados en los análisis de la geometría de secciones transversales a $65 \%$ de la longitud total de las tibias. Entre los individuos de Nombre de Jesús, NdJ3 es el que presenta propor-

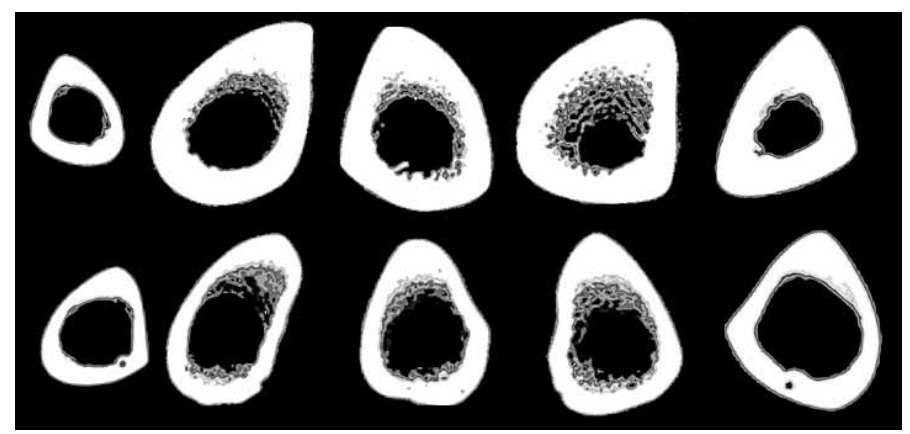

Fig. 8. Cortes transversales de tibia a 35\% (arriba) y 65\% (abajo) de la longitud total (el extremo proximal es 100\%). De derecha a izquierda NDJ1, NdJ2, NdJ3, NdJ4 y NdJ5. 


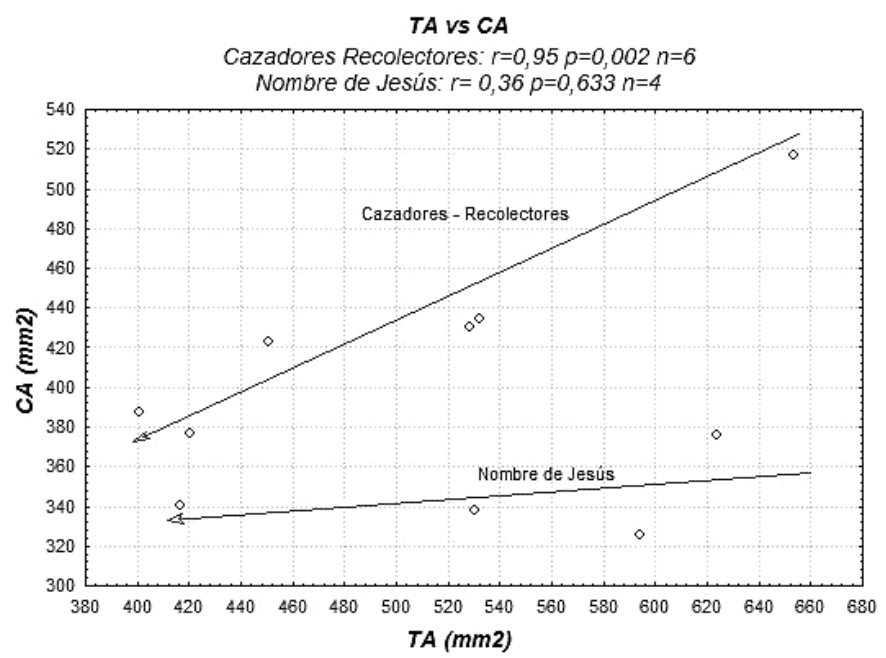

Fig. 9. Área total vs. área cortical de los individuos de Nombre de Jesús en la sección del 35\% de las tibias, en comparación con análisis de individuos cazadores recolectores de Patagonia Austral.

cionalmente mayor TA, aunque es el individuo que mayor reducción de $\mathrm{CA}$ muestra en relación a lo esperado tomando como referencia los resultados de cazadores recolectores. Por el contrario, los análisis de indicadores biomecánicos relacionados con las cargas mecánicas (momentos de área y momento polar -I y J respectivamente), no mostraron diferencias significativas entre los individuos de Nombre de Jesús y los cazadores recolectores explorados, tanto en las secciones al 35\% (Figura 10) como al 65\% de las tibias. Entre los individuos de Nombre de Jesús,
NdJ2 presentó una menor circularidad y un mayor valor del indicador de fuerzas de torsión (J), por lo que la actividad física desarrollada habría estado relacionada con mayores cargas sobre el eje mayor de la geometría del corte transversal de la tibia a los niveles estudiados. Por el contrario, el resto de los individuos presentó una geometría mas circular sobre la tibia y probablemente menos sujeta a stress mecánico que el individuo NdJ2 (Tabla 6 y Figura 8). Por otra parte, las tendencias en los valores de indicadores de flexión y torsión (I y J) resultaron

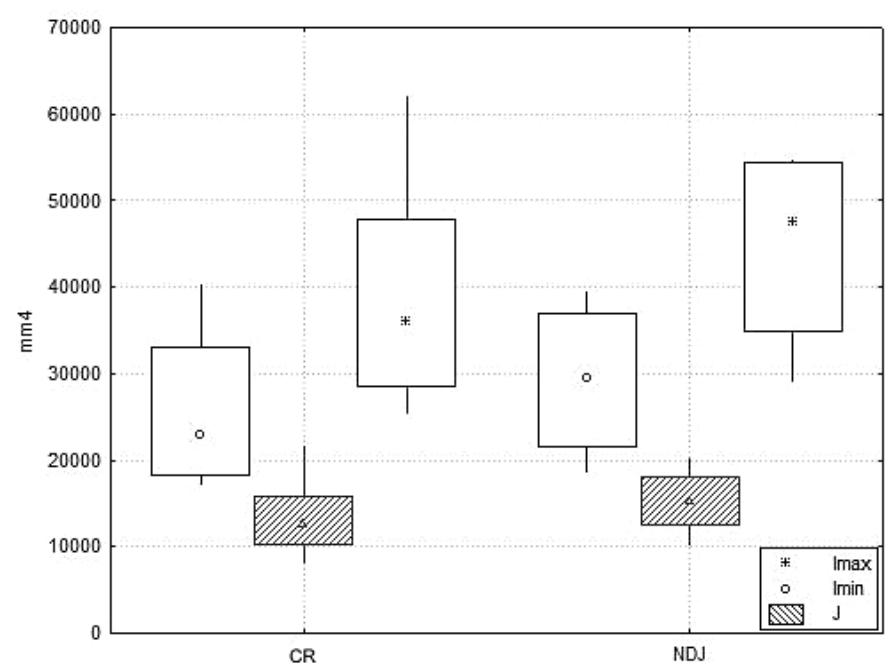

Fig. 10. Representación comparativa de las estimaciones de Imax, Imin y J para la sección transversal al $35 \%$ de las tibias de Nombre de Jesús (NdJ) y cazadores recolectores (CR) de Patagonia Austral. 
Tabla 6. Estimaciones de indicadores biomecánicos de cortes transversales de tibia a 35\% desde el extremo distal.

\begin{tabular}{|c|c|c|r|r|r|r|}
\hline Esqueleto & TA & CA & MA & Imax & Imin & J \\
\hline NDJ 2 & 594,070 & 325,890 & 268,18 & 39547,67 & 14629,11 & 4176,78 \\
\hline NDJ 3 & 624,050 & 375,940 & 248,11 & 34500,48 & 20235,31 & 54735,79 \\
\hline NDJ 4 & 530,520 & 337,630 & 192,89 & 24616,11 & 16113,29 & 40729,40 \\
\hline NDJ 5 & 416,940 & 340,590 & 79,35 & 18721,18 & 10345,27 & 29066,45 \\
\hline
\end{tabular}

similares entre los individuos de Nombre de Jesús y los cazadores recolectores evaluados.

\section{DISCUSIÓN Y CONCLUSIONES}

Los estudios paleopatológicos realizados sobre Nombre de Jesús permiten evaluar aspectos relacionados con la salud de los primeros colonizadores europeos en Patagonia, la posibilidad de introducción de patologías infecciosas e interpretarlos a través del contraste con las expectativas originadas en relatos históricos. Los resultados hallados mostraron principalmente altas frecuencias de lesiones metabólicas-nutricionales, seguidas por lesiones infecciosas y osteoarticulares (Tabla 7). Entre las primeras se registraron altas frecuencias de evidencias de síndrome porótico activos, particularmente en el hueso parietal y occipital, acompañado de desmineralización ósea trabecular y alteraciones del tejido cortical en la mayoría de los individuos adultos, evidenciado a través de los análisis densitométricos y de la geometría transversal de huesos largos. Además, todos los casos presentaron hipoplasia del esmalte dental, y evidencias de líneas de Harris y líneas de refuerzo trabecular en huesos largos. Teniendo en cuenta que los individuos murieron a temprana edad, entre los 18 y 26 años en el caso de los adultos, y uno siendo aún niño (entre 10 y 12 años), estos resultados tienden a favorecer la hipótesis planteada anteriormente de que los pobladores habrían estado sujetos a importantes trastornos metabólicos-nutricionales. Es decir, la conjunción de estas líneas de evidencia favorece la hipótesis de procesos de malnutrición, que los afectaron tanto durante su periodo de desarrollo (evidenciado por líneas de harris e hipoplasia del esmalte), como durante su adultez (desmineralización y alteración del tejido cortical y esponjoso).

Reconocer el momento en el cual tales lesiones fueron desarrolladas resulta complejo. Cabe preguntarse si los procesos de malnutrición observados se desarrollaron como resultados del extenso viaje hasta la Patagonia, o ya habían afectado a estos individuos antes de su travesía. Para interpretar el momento de ocurrencia de estos trastornos se debe considerar que el viaje se extendió aproximadamente por tres años, mientras que el asentamiento en el sur de Patagonia se prolongó algunos meses (Martinic 1978). Por consiguiente, algunas de las lesiones observadas, incluyendo las líneas de hipoplasia y líneas de Harris, procesos que se producen durante la niñez, y considerando la edad a la muerte de los adultos, habrían sido producidas antes de embarcarse hacia América o durante la travesía.

En cuanto a los trastornos observados en la desmineralización del tejido esponjoso (osteopenia) y las alteraciones del tejido cortical, aunque no puede descartarse que existieran en momentos previos al asentamiento en Patagonia, es probable que se ha-

Tabla 7. Cuantificación de lesiones de acuerdo a su etiología en cada uno de los individuos de Nombre de Jesús.

Las lesiones metabólicas y nutricionales incluyen líneas de Harris, síndrome porótico (hiperostosis porótica, femoral y criba orbitalia), trastornos corticales, reducción de la DMO e hipoplasia del esmalte dental.

\begin{tabular}{|c|c|c|c|c|c|c|}
\hline & $\begin{array}{c}\text { Metabólicas- } \\
\text { Nutricionales }\end{array}$ & Traumáticas & Congénitas & Infecciosas & Vasculares & Osteoarticulares \\
\hline NdJ 1 & 3 & 0 & 0 & 0 & 0 & 0 \\
\hline NdJ 2 & 5 & 2 & 0 & 2 & 0 & 3 \\
\hline NdJ 3 & 5 & 1 & 1 & 5 & 0 & 3 \\
\hline NdJ 4 & 4 & 1 & 1 & 2 & 0 & 0 \\
\hline NdJ 5 & 2 & 0 & 1 & 1 & 0 & 0 \\
\hline Total & 19 & 4 & 3 & 10 & 0 & 6 \\
\hline$\%$ & 45,25 & 9,5 & 7,15 & 23,8 & 0 & 14,3 \\
\hline
\end{tabular}


yan acentuado durante la existencia de Nombre de Jesús, dada su evolución y su estado activo, al igual que el tipo de de lesiones hiperostósicas halladas en la mayoría de los individuos.

Las altas frecuencias de lesiones de origen infeccioso inespecífico podrían estar en relación con los hallazgos de trastornos nutricionales, debido a las fallas inmunológicas que la malnutrición ocasiona, facilitando el desarrollo de infecciones oportunistas. En el caso del individuo NdJ 4 estas infecciones podrían haber resultado críticas, debido al desarrollo de osteomielitis y que podría haber sido causa de muerte, considerando además la ausencia de otras lesiones periósticas en el resto del esqueleto. Los otros individuos adultos presentan lesiones infecciosas con menor grado de desarrollo y que afectaron mayor número de elementos (tal el caso de $\mathrm{NdJ3}$ ). Estos resultados se acompañan además por los obtenidos por Fugassa (2006), según los cuales se hallaron restos de infecciones por parásitos hallados frecuentemente en letrinas del mismo periodo en Europa. Por el contrario, no se evidenciaron lesiones compatibles con infecciones específicas, tales como tuberculosis, lepra, sífilis, entre otras, que pudieran significar focos de infección transmisible a las poblaciones nativas americanas, aunque esta posibilidad no puede ser descartada.

Bajo la impresión diagnostica de malnutrición, y tratándose de individuos pertenecientes a navegadores europeos del siglo XVI, se consideró la posibilidad de desarrollo de escorbuto, es decir deficiencias de Vitamina C. Sin embargo, las lesiones que responden a esta patología en general comprenden extensas pérdidas dentales y la presencia sistémica de lesiones periosticas dispersas por toda la anatomía (costillas, cráneo, miembros superiores $e$ inferiores). En todos los individuos se observaron escasas pérdidas dentales y lesiones periosticas limitadas en general a huesos de las extremidades. En este sentido, el diagnóstico diferencial se orienta a fortalecer la causa infecciosa de estas lesiones.

Menores son las lesiones osteoarticulares, aunque en particular el individuo NdJ3, identificado como el único individuo de sexo femenino de la muestra, presentó severas lesiones vertebrales. Los cuerpos vertebrales dorsales mostraron extensas lesiones compatibles con hernias de disco, que estarían asociadas a importantes cargas mecánicas a ese nivel, además de una lesión osteoarticular en la escápula derecha y una fractura costal. Este individuo además presentó los mayores indicadores biomecánicos, por lo que habría estado sujeto a un estilo de vida asociado a intensos trabajos de carga mecánica. Finalmente, se registraron anomalías congénitas en tres de los individuos, aunque en todos los casos habrían sido asintomáticos y sin implicaciones patológicas.

Hasta el momento no han sido recuperados otros restos óseos humanos en el sitio Nombre de Jesús. Los trabajos de exploración del asentamiento continúan, por lo que esperamos que en el futuro nuevas evidencias sean halladas, aportando mayor información acerca de la trágica historia en la que se vio envuelto un conjunto de hombres, mujeres y niños que intentaron colonizar un territorio para ellos inhóspito y lejano.

\section{AGRADECIMIENTOS}

Nuestro agradecimiento al Dr. Luis A. Borrero, al Museo Regional Provincial Padre Jesús Molina y a quienes participaron en los trabajos de campo. A los Dres. Sheila Mendonça de Souza y Conrado Rodríguez Martin. Las campañas fueron realizadas con financiamiento Proyecto UBACyT F-076 (20042007) "Sociedad Moderna y Cultura Material" y Fundación Antorchas Subsidio Inicio de Carrera “Tiempos Modernos en Patagonia"(2004-2007). Los estudios paleopatológicos y bioarqueologicos fueron realizados con financiamiento del Proyecto PICT 01520 "Paleoepidemiología en Tierra del Fuego". Los estudios radiográficos fueron realizados con la colaboración de los Dres. Sebastián Constantino y Carlos Capiel, en el Instituto Radiológico de Mar del Plata (Argentina). Los estudios densitométricos se llevaron a cabo gracias a la colaboración del Dr. Oscar Varela, en el Hospital Privado de Mar del Plata (Argentina) y los estudios tomográficos biomecánicos se realizaron en conjunto con los Dres. José Luis Ferretti y Gustavo Cointry en el Centro de Estudios del Metabolismo Fosfocálcico, de la Universidad Nacional de Rosario (Argentina). Al Dr. Gabriel Fonseca (Laboratorio de Odontoestomatología, Universidad Nacional de Córdoba) por sus comentarios en relación a las patologías dentales. A los evaluadores anónimos de este trabajo, quienes con sus comentarios ayudaron a mejorar el manuscrito inicial. 


\section{BIBLIOGRAFÍA}

AGARWAL; SC. DIMITRIU, M. y GRYNPAS, M.D. 2004. Medieval Trabecular Bone Architecture: The Influence of Age, Sex and Lifestyle. American Journal of Physical Anthropology 124(1):33-44.

AUFDERHEIDE, A.C. y RODRIGUEZ MARTIN, C. 1998. The Cambridge Encyclopedia of Human Paleopathology. Cambridge University Press. UK.

BARROS, J.M. 1978. Primer testimonio de Tomé Hernández sobre las fundaciones hispánicas del Estrecho de Magallanes. Anales del Instituto de la Patagonia 9:65-76

-1991-1992. Rey Don Felipe: plano de una fundación hispana en el Estrecho de Magallanes. Boletín de la Academia Chilena de la Historia. Nro 102, pp. 387401. Santiago.

BENITES, MARÍA JESÚS. 2004. Con la lanza y con la pluma. La escritura de Pedro Sarmiento de Gamboa. Tucumán: Instituto Interdisciplinario de Estudios Latinoamericanos. Tucumán: Facultad de Filosofía y Letras, Universidad Nacional de Tucumán.

BORRERO, LA. y FRANCO, N.V. 1999. Arqueología de Cabo Vírgenes, Provincia de Santa Cruz. En Actas del XIII Congreso Nacional de Arqueología Argentina, Córdoba, en prensa.

BUIKSTRA, J.E. y UBELAKER, D.H. 1994. Standars for data collection from human skeletal remains. Arkansas Archaeological Survey Research Series $N^{\circ} 44$. Arkansas, USA.

BYERS, S. 1991. Technical Note: Calculation of Age at Formation of Radiopaque Transverse Lines. American Journal Of Physical Anthropology 85:339-343.

CAMPILLO, D. 2001. Introducción a la Paleopatología. Bellaterra Arqueología. España.

CAPASSO, L. KENNEDY, KAR y WILCZAK, C.A. 1999. Atlas of Occupational Markers on Human Remains. Journal of Paleontology. Monographic Publicacion 3. Edigrafital S.p.A. Teramo. Italia.

CUPPAGGE, FE. 1995. Scurvy's conquest and sailors' health. Historian 57(4):695:703.

DE NIGRIS, MARIANA. PALOMBO, PAULA y MARÍA XIMENA SENATORE. 2008. Craving for hunger: a zooarchaeological study at the edge of the Spanish Empire. En Anthropological Approaches to Zooarchaeology: Colonialism, Complexity and Animal Transformations. Douglas Campana, Pam Crabtree y Alice Choyke (eds.). Oxford: British Archaeological Reports, International Series. En prensa.
EKENMAN, I. ERIKSSON, S.A. y LINDGREN, J.U. 1995. Bone density in medieval skeletons. Calcif Tissue Int 56:355-358

FERNANDEZ, J. 1983. Arqueología de la Ciudad del Nombre de Jesús. En: Presencia Hispánica en la Arqueología Argentina, E. Morresi y R. Gutierrez (eds.), vol 2, pp. 895-930 Resistencia.

-1990. Análisis de las Causas Concurrentes al fracaso de las Colonias Españolas de 1584 en el estrecho de Magallanes, Patagonia Austral. En: Culturas Indígenas de la Patagonia editado por J. R. Bárcena, pp. 63-113. Sociedad Estatal Quinto Centenario, Producción Turner S. A. Madrid.

FUGASSA, M.H. 2006. Enteroparasitosis en poblaciones cazadoras-recolectoras de Patagonia Austral. Tesis Doctoral. Facultad de Ciencias Exactas y Naturales. Universidad Nacional de Mar del Plata.

ISCAN, M.Y. LOTH, S.R. y WRIGHT, R.K. 1984. Metamorphosis at the sternal rib end: a new method to estimate age at death in white males. American Journal of Physical Anthropology 65:147-156.

BASS, W.M. 1995. Human Osteology. A laboratory and field manual. Spetial Publicacion No. 2 of the Missouri Archaeological Society. Columbia. Third Edition, Fifth printing.

KNEISSEL, M. ROSCHGER, P. STEINER, W. SCHAMALL, D. KALCHHAUSER, G. BOYDE, A. y TESCHLERNICOLA, M. 1997. Cancellous bone structure in the growing and aging lumbar spine in a historic Nubian population. Calcif Tissue Int 61:95-100.

LARSEN, C.S. 1997. Bioarchaeology: Interpretin behavior from human skeleton. Cambridge University Press. Cambridge. UK.

LEES, B. MOLLESON, T. ARNETT, T.R. y STEVENSON, J.C. 1993. Differences in proximal femur bone density over two centuries. Lancet 341:673-675.

LEVIS, A. y ALTMAN, R. 1998. Bone Densitometry. Clinical considerations. Arthritis Rheum. 41:577-587.

MAAT, G.J.R. 2004. Scurvy in adults and youngsters: the Dutch experience. A review of the history and pathology of a disregarded disease. International Journal of Osteoarchaeology 14(2):77-81.

MARTINIC, M. 1978. Nombre de Jesús, una población de ubicación incierta. Anales del Instituto de la Patagonia 9:53-64; Punta Arenas.

-1983. El Reino de Jesús. La efímera historia de una Gobernación en el Estrecho de Magallanes (1581-1590). Anales del Instituto de la Patagonia 14: 7-32.

-2003. Ciudad de Rey Don Felipe (Estrecho de Magallanes, Chile). Consideraciones acerca de su defensa. Magallania 31: 5-13, Chile. 
MASSONE, M. 1983. Antecedentes arqueológicos en torno a la ocupación española del siglo XVI en Punta Dúngenes (Patagonia Meridional). Anales del Instituto de la Patagonia 14: 49-54, Punta Arenas.

MAYS, S. LEES, B. y STEVENSON, J.C. 1998. Age-dependent bone loss in the femur in a medieval population. International Journal of Osteoarchaeology 8: 97-106.

MAYS, S. TURNER-WALKER, G. y SYVERSEN, U. 2006. Osteoporosis in a population from medieval Norway. Am. J. Phys. Anthropol. 131:343-351.

MAYS, S. 1996. Age-dependent cortical bone loss in a medieval population. International Journal of Osteoarchaeology 6:14-154

MAYS, S. 1999. Osteoporosis in earlier human populations. J. Clin Densitom 2:71-78.

MAYS, S. 2006. Age-related cortical bone loss in women from a 3rd-4th century AD population from England. American Journal of Physical Anthropology 129 (4):518-528. OMS Consensus Conference. 1984: Osteoporosis. Jama 252-799.

ORTNER, D.J. 2003. Identification of Pathological Conditions in Human Skeletal Remains, 2nd ed. Elsevier Science/ Academic Press, New York.

ORTIZ TRONCOSO, O. 1970. Excavación Arqueológica de la Iglesia del poblado hispánico de Rey Don Felipe (Patagonia Austral Chilena). Anales del Instituto de la Patagonia 1: 5-13, Punta Arenas.

-1971a. Arqueología de los poblados hispánicos de la Patagonia Austral, Segunda Etapa de las excavaciones en Rey Felipe y nuevos antecedentes sobre nombre de Jesús. Anales del Instituto de la Patagonia 2(1-2):3-19, Punta Arenas.

-1971b. Antecedentes sobre Nombre de Jesús. Anales del Instituto de la Patagonia 2 (1-2): 3-17, Punta Arenas. -1971c. Rey Don Felipe, ciudad hispánica del siglo XVI en la Patagonia. Su redescubrimiento por la arqueología. Revista General de Marina, Marzo: 1-8, Madrid.Antecedentes Históricos y Arqueológicos sobre el poblado hispánico de Nombre de Jesús (Patagonia Austral). Revista General de Marina, Marzo: 3-11, Madrid. -1992. Un Alcance al Tema de la Cerámica Hispana en Patagonia Austral, Journal de la Société des Américanistes, LXXVIII: 73-85, París.
PASTELLS, P. 1920. El Descrubrimiento del Estrecho de Magallanes. Sociedad Hispanoamericana de Historia, Madrid.

PÉREZ MARTÍN, S. ANTONA MONTORO, A.M. RODRÍGUEZ GONZÁlEZ, A.I. y GONZÁLEZ MARTÍ, A. 1999. Macroporosidad del Cuello del Fémur en la población hispanomusulmana de San Nicolás (Murcia s. XI-XIII). V Congreso Nacional de Paleopatología. Alcalá La Real. p. 6.

ROSENBLAT, ÁNGEL. 1950. Pedro Sarmiento de Gamboa. Viajes al Estrecho de Magallanes (1579-1584). Recopilación de sus relaciones sobre los dos viajes al Estrecho y de sus cartas y memoriales. Con un apéndice documental sobre su vida y sus viajes 2. Buenos Aires: Emecé Editores.

SARAVIA VIEJO J. 1988 Pedro Sarmiento de Gamboa. Viajes al Estrecho de Magallanes. Madrid.

SENATORE, M.X. DE NIGRIS, M. GUICHÓN, R.A. y PALOMBO, P. Arqueología en la Ciudad del Nombre de Jesús: Vida y Muerte en el Estrecho de Magallanes a Fines del Siglo XVI. 2007. En: Arqueología de Fuego-Patagonia. Levantando piedras, desenterrando huesos... y levantando arcanos. Ediciones CEQUA. pp. 779-786.

STEINBOCK, R.T. 1976. Paleopathological Diagnosis and Interpretation. Bone diseases in ancient human population. Ed. Charles E. Thomas.

SUTER, S. HARDERS, M. PAPAGEORGOPOULOU, C. KUHN, G. SZÉKELY, G. y RÜHLI, F.J. 2008. Technical Note: Standardized and Semiautomated Harris Lines Detection. American Journal of Physical Anthropology 137:362-366.

TARLI, S.B y PACCIANI, E. 1993. I resti umani nello scavo archeologico. Bulzoni, Roma 1993.

TROTTER, M. y GLESSER, G.C. 1952. Estimation of stature from long bones of American whites and Negroes. American Journal of Physical Anthropology 19:213:227.

TROTTER, M. y GLESSER, G.C. 1958. A re-evaluation of estimation based on measurements of stature taken during life and of long bones after death. American Journal of Physical Anthropology 16:79-123.

UBELAKER, D.H. 1989. Human skeletal remains: Excavation, analysis and interpretation. 2nd ed. Washington DC, Taraxacum Press. 